\title{
US Investments in International Climate Research and Applications: reflections on contributions to interdisciplinary climate science and services, development, and adaptation
}

Lisa Farrow Vaughan ${ }^{1 *}$, John Furlow², Wayne Higgins ${ }^{1}$, Claudia Nierenberg ${ }^{1}$ and Roger Pulwarty ${ }^{3}$

\begin{abstract}
Climate variability and change have long posed substantial challenges for social, economic and natural systems throughout the world. Incorporating information about climate fluctuations and their impacts is an increasingly important component of risk management and planning in key socio-economic sectors. Understanding and meeting these challenges through effective risk management strategies that foster preparedness, impact mitigation, and adaptation requires a long-term investment in and commitment to sound science, transition, and translation of information among communities, and the application and evaluation of climate services and decision support resources. This science should be developed, implemented and applied in the context of the practical needs and capabilities of communities, stakeholders, and socio-economic sectors if it is to inform resource management challenges, and contribute to the field of study of climate, climate information services, preparedness and adaptation.

During the early 1990s, the United States expressed a desire to capitalize on emerging developments in atmospheric and oceanic research and early climate impact studies, in order to develop the institutional capacity to meet these needs on global and regional scales. As a member of the US Global Change Research Program (USGCRP), and working in partnership with the international scientific and governmental community, NOAA led the development of an international research institute, which is known today as the International Research Institute for Climate and Society (IRI). Over several decades - from the initial conceptual and demonstration phases, to today's mature institution - IRI had a substantial influence in linking science and action to risk management. This essay briefly reflects upon the initial vision for and evolution of the IRl; the importance of investments in endeavors of this nature to the US climate research and services communities, including model development, climate prediction and integrated research and assessments; and the value of such an institution to a Federal entity concerned with development and risk management in developing countries - the US Agency for International Development (USAID). We conclude with some thoughts about future directions.
\end{abstract}

Keywords: Interdisciplinary climate research; Climate variability and change; Resilience; Climate services; International cooperation; Climate and development

\footnotetext{
* Correspondence: Lisa.Vaughan@noaa.gov

${ }^{1}$ Climate Program Office, National Oceanic and Atmospheric Administration,

US Department of Commerce, 1315 East-West Highway, Silver Spring, MD

20190, USA

Full list of author information is available at the end of the article
} 


\section{Report}

\section{The challenge}

Climate variability and change have long posed substantial challenges for social, economic and natural systems throughout the world. The seasonality of certain hazards, such as hurricanes, droughts, and floods, already provides policymakers with clear indications of regions that are potentially at risk (National Research 1999). Incorporating information about climate fluctuations and their impacts is an increasingly important component of risk management and planning in key socio-economic sectors. Understanding and meeting these challenges through effective risk management strategies that foster preparedness, impact mitigation, and adaptation requires a long-term investment in and commitment to sound science, transition and translation of information among communities, and the application and evaluation of climate services and decision support resources. We define "climate services" for the purpose of this article to mean "The timely production and delivery of useful climate data, information and knowledge to decision makers" (National Research Council 2001).

This special issue of Earth Perspectives: Transdisciplinarity Enabled provides a unique opportunity for describing - from various perspectives - the roots, methodology, and impact of the International Research Institute for Climate and Society (IRI). The landscape for international climate services and the use of climate information in critically important decision-making has evolved significantly over the last couple of decades. The demand for useful and forwardlooking information about climate variability and change across time scales has exploded during this period, as evidenced by a growing focus on climate and risk management/adaptation in many sectors, countries and regions. Stakeholders and decision makers are demanding tangible, actionable information on the impacts of a dynamic climate system on the lives, livelihoods and property of the people and places in which they are vested. Increasingly, meeting these needs has meant the creation of data, contextual socio-economic information, decision support tools and institutional capacity to reduce the negative consequences and take advantage of the positive impacts of variability and change. In addition, the last $10-15$ years also marks an increasing recognition by institutions with development and resource management mandates (e.g., The World Bank and regional development banks, the World Health Organization) of the need to consider strategic approaches to addressing a dynamic climate system within their relevant sectors (World Bank climate change programs; World Health Organization climate programs).

In many respects, IRI may serve as a useful experience for the next generation of international - and potentially regional and national - climate research and services that empower society to enhance social, environmental and economic resilience in the face of a changing climate system.

\section{NOAA's role in the vision and evolution of the International Research Institute for Climate and Society}

The concept of an International Research Institute for climate prediction (IRICP) - which ultimately evolved into today's IRI - dates back to the 1980s and the findings of the international Tropical Oceans-Global Atmosphere (TOGA) Program. The TOGA Program was a large scale, scientific research effort designed to understand, and ultimately predict, short-term (weeks, months, seasons) climate variations. Doing so required focused and purposeful collaboration among researchers from different disciplines. Throughout the decade long program, the scientists and countries involved in TOGA recognized that this multi-disciplinary, international cooperation was key to developing a confident ability to forecast seasonalto-interannual fluctuations in climate.

It became increasingly clear to many involved in the TOGA Program, including NOAA and other US science agencies (e.g., the National Aeronautics and Space Administration (NASA), the National Science Foundation (NSF)) that the time was ripe to begin exploring how these new scientific breakthroughs brought about by trans-disciplinary, international collaboration in process studies - as well as the associated observations, monitoring, assessment and modeling capabilities - could generate information products and decision support tools that could be utilized for planning, preparation, and disaster mitigation in the face of El Niño-Southern Oscillation (ENSO) related extreme events such as droughts and floods. This potential was particularly important in the tropical regions -where the prediction of ENSO-related teleconnections seemed to be highest at the time (National Research Council 1996; Ropelewski \& Halpert 1987) - and where lives and livelihoods tend to be more sensitive to climate variations (Glantz 2000). In 1989, a Presidential Initiative established the US Global Change Research Program (USGCRP), which links portions of research budgets across 13 agencies. Congress then passed the Global Change Research Act of 1990, which mandated, among other requirements, international research and cooperation, and interactions with users of the Program's findings to ensure the usability of Federal research investments (US Global Change Research Program).

The basic mandate of the 1991 "Our Changing Planet", the annual USGCRP report to Congress, was to:

1. Integrate science into the policy process

2. Maintain partnerships among all participants

3. Focus on interdisciplinary science and interactions 
While many interpreted this directive to mean linking physical science models with economic and other models, the NOAA Office of Global Programs (OGP) envisioned a more interactive process with decision makers. Additionally, the NOAA/OGP support of climate variability research and seasonal forecast development resulted in an early emphasis on changes in the higher moments of the climate system in addition to changes in the mean state. For instance, both stochastic and deterministic elements of key processes were seen as fundamental to understanding ENSO variability and change. In this context the climatic time scale would come to be treated as a continuum rather than as completely discrete modes of variability in which change was a wholly separable component (Pulwarty et al. 1999).

This new structure brought about by the USGCRP was a watershed moment as it identified the potential value of emerging developments in the earth sciences as an underlying justification for a substantial, and sustained US investment in interdisciplinary and international research for the benefit of society. There were two important roots of this focus: the early successes in predictability of the ENSO phenomenon, and the interest in developing climate information services relevant to decision makers, especially in the agriculture community at that time. Reliable, probabilistic information on short term climate fluctuations that had some degree of regional specificity would be the most relevant to planning and preparedness and would be the right foundation for a true climate service, globally and locally. Over the following years, it became increasingly clear, however, that a prediction alone was not enough to achieve benefits to society; to do so requires knowledge of the regional context, including the socio-economic and cultural aspects, in which this which information is presented, and the capacity to analyze and incorporate climate information into existing decision making processes. These concepts became the guiding strategic goal of both the NOAA international and domestic program investments throughout much of the 1990s (The NOAA Panel on Climate and Global Change 1989).

For its contribution to the new cross-agency program, NOAA focused almost exclusively on its comparative advantage in seasonal-to-interannual climate prediction. The focus across investments in observations, modeling, process research, as well as the early efforts to fund investigations in social science and impacts studies, was on improvements to short term climate forecasts and on developing and refining regional scale information. Knowing more about earth system processes, particularly climate, it was argued, would matter to people around the world in very visible and direct ways - to food production and security, disaster management, water management, public health, and livelihoods in general. The US, and in particular NOAA, was now well positioned to capitalize on the potential societal return on these international investments (Testimony of J. Michael Hall, Director, Office of Climatic and Atmospheric Research, Office of Oceanic and Atmospheric Research, National Oceanographic and Atmospheric Administration, U.S. Department of Commerce 1987).

In addition to the USGCRP, NOAA underwent some institutional changes that became extremely relevant over time to our international efforts and eventually resulted in the collaboration between the two entities in the development of innovative forecast products (see below). In 1979, the agency invested in the development of a Climate Analysis Center (which later became the Climate Prediction Center), which sought to develop the necessary operational climate prediction capabilities for the Nation following the strong 1982-1983 El Niño event. Years later, the relationship between the NOAA Climate Prediction Center (CPC) with institutions such as the IRI and others was essential to the ultimate enhancement of this capability, upon which much of the US relied upon during the 1997-1998 and subsequent ENSO events.

In 1989, the International TOGA Scientific Steering Group (TOGA/SSG) recommended the creation of a "Centre or centres for the study of climate predictability and the development of quasi-operational prediction schemes" (JSC/CCCO TOGA Scientific Steering Group 1990). Over the ensuing half decade, this initial concept was further explored through an international dialogue. Scientists and governments identified the need for an "end-to-end" globally distributed network of activities that would foster the translation of cutting edge research on seasonal-tointerannual timescales (including the associated observations, predictions, diagnostics and impacts studies) into regional applications, decision support services, and early warning networks. The initial concept envisaged by NOAA and others would be to centralize some of the research, modeling and prediction functions at a "core" center, while decentralizing other functions such as the development of regional applications for this information, capacity building and institutional network development in order to address specific risk management needs and develop place-based capabilities. These concepts were outlined in a plan developed by an international group of scientists and government representatives in 1992 (Task Group for the International Research Institute for Climate Prediction 1992). In parallel, at the 1992 United Nations Conference on Environment and Development (UNCED), the US invited "government officials and scientists from all interested nations to join in developing an International Research Institute for Climate Prediction" (United States Government 1992) that would generate and apply innovative scientific information about climate variability to decision making in climate-sensitive sectors such as agriculture, water resources, emergency planning 
and preparedness and human health. As part of its contribution to the IRI development, NOAA developed a Proposal to Launch a Seasonal-to-Interannual Climate Prediction Program, which provided the agency's perspective on the types of programs, resources and cooperation that would be needed, including with NOAA's National Meteorological Center (which has since been reorganized into the National Centers for Environmental Prediction), and across the newly formed USGCRP, if these advances in science were to be recognized (The National Oceanic and Atmospheric Administration 1994). In 1995, NOAA convened the International Forum on Forecasting El Niño: Launching an International Research Institute, in Washington DC (NOAA Office of Global Programs 1996). Shortly afterwards, with the encouragement and input of the intergovernmental and scientific community represented at the Forum and in previous events, NOAA awarded the initial IRI grant to a consortium of universities- the Lamont Doherty Earth Observatory of Columbia University and the Scripps Institute of Oceanography of the University of California, San Diego.

Recognizing that the benefits to society of an IRI could only be achieved if the knowledge and capacity to utilize experimental predictions (as well as understanding of current climatic conditions) existed beyond the traditional scientific community, NOAA/OGP had initiated a series of pilot projects beginning in the early 1990s. This effort was housed within a research arm of the agency, the Office of Global Programs (OGP), to ensure that it was guided by the same rigorous standards of project development, review and implementation utilized in the physical science programs. It was integrated with OGP's physical and social science research programs in order to generate the most usable interdisciplinary outcomes; recognized by as innovative, credible scientific research, undertaken in a realm uninfluenced by some of the high level, controversial international climate negotiations underway at the time. NOAA's suite of activities consisted of the regional Pilot Program for the Application of Climate Forecasts, and the Regional Climate Outlook Forums (RCOFs) in which regional-specific forecasts and the results of the Pilot Program research were presented. Each one was designed and undertaken in conjunction with a wide range of partners including, inter alia, the US Agency for International Development's Office of Foreign Disaster Assistance (USAID/ OFDA); the NOAA/CPC); the World Meteorological Organization (WMO) and its member National Meteorological and Hydrological Services (NMHS) in some countries; the World Bank; several regional research networks endorsed by the 1992 UNCED focused on the Americas, Africa and Asia (e.g., the Inter-American Institute for Global Change Research, the European Network for Research in Global Change); the United Kingdom Meteorological Office, and the Asian Disaster Preparedness Center.
NOAA's regional Pilot Applications Program focused on Latin America and the Caribbean; Africa; and Asia. In each region, NOAA's approach was influenced by concepts such as those expressed by Dr. Michael Glantz in 1995:

"If El Niño events can be forecast some months in advance, societies could prepare to prevent or to mitigate their impacts (at least in theory). In practice, of course, societies-i.e. governments, corporations and individuals -respond in different ways to the threat of impending natural hazards. Some societies are risk averse and tend to prepare early; others are risk-takers and may not take preventative measures at all. Societal responses depend on many factors, including the credibility of the forecasters, the ability of government to engage in disaster preparedness, and the ability of a government to communicate to its citizens the risks involved with the occurrence of such a potentially disastrous event such as El Nino" (Glantz 1995).

NOAA's efforts in each region were composed of four key elements: 1) Preparatory Studies, consisting of initial impacts and vulnerability studies and discussions of the potential for climate information to reduce the effect of climate-related impacts in sectors such as agriculture and food security, water resource management, human health, and disaster preparedness; 2) Capacity Building for Applying Climate Forecasts, composed of presenting the results of the first element, and the initiation of shorterterm pilot projects that involved linking the understanding of impacts and vulnerability to the production and distribution of experimental outlook information products to decision makers in vulnerable sectors; 3) Institutionalizing Climate Forecasting Applications Networks, which focused on the advancement of regional networks to produce, distribute, apply and evaluate experimental forecasts for decision making; and 4) Review and Evaluation, including the review and the provision of input on each activity element, and regional training and capacity building in the context of the above activities (Buizer et al. 2005).

During the first half of the 1990s, these activities laid the groundwork for a real-time global "experiment" triggered by nature: the 1997-1998 El Niño event, one of the strongest such events of the century with very substantial global impacts. In part due to the efforts of NOAA's Pilot Applications Program and its wide suite of partners, several national, regional and international entities were well-positioned to build upon the knowledge gained in the first half of the decade about stakeholder needs, potential applications and forecast provision, and launch a response to the '97-'98 event. The RCOFs served as the core of this effort in many regions as mechanisms through which NOAA and its many partners brought together oceanographers, climatologists, meteorologists and other physical scientists to develop a 
shared expectation of the impacts of the event on the precipitation and temperature patterns of their region. This consensus information was shared with social scientists and stakeholders who could make linkages to potential uses for this information, based on knowledge about the impacts on a particular sector ${ }^{\mathrm{a}}$. The outcomes of this process - the nature of which varied by region and even sub-region - were shared with the public in many cases, either through the NMHS, public conferences, academic institutions, trade associations, and/or the media. During the '97-'98 event itself, NOAA and its partners led the organization of a total of 11 RCOFs in the Americas, Africa and Asia ${ }^{\mathrm{b}}$. The IRI was up and running at this point, and so its experts took on increasingly important technical roles in pilot applications activities and the $\mathrm{RCOF}$ processes in many regions.

Informed by these initial activities and by the ensuing projects and partnerships (many of which are addressed in this special issue of Earth Perspectives), NOAA, USAID, the IRI and their many partners throughout the world were taking concrete steps toward building the components and linkages of an international, end-to-end network envisaged by the TOGA Program over 10 years earlier. Increasingly, the concept of risk management is noted as a core principle of the effort. In 2005, the IRI adopted a new name - the current International Research Institute for Climate and Society - to reflect the importance of incorporating research into the socio-economic aspects of producing, applying and evaluating the impact of climate information in specific places and sectors. This expansion was encouraged by NOAA, and paralleled the development of NOAA's own efforts to build a research portfolio that linked climate information with the actual needs and decision makers, including the NOAA Regional Integrated Sciences and Assessments (RISA) Program, and others that now comprise the agency's Climate and Societal Interactions (CSI) Program.

\section{Rationale for US Investments in International Climate Research and Applications Programs}

Why did NOAA make these international investments, given the extensive effort and resources necessary for implementing effective pilot projects, and building information networks and the critical partnerships needed to sustain early warning and risk management systems? The primary goal behind the agency's investment in these international activities was to engage a wide network of disciplines, national, regional and international organizations - including decision makers and stakeholders - in exploring the potential opportunities and institutional barriers to generating, distributing and utilizing information about today's climate, as well as emerging predictions of short term fluctuations, such as the type that would be generated by IRI, NOAA/CPC and other entities. The rationale guiding our efforts was two-fold.

From the earliest days, many in NOAA viewed the IRI and the associated regional activities not only as a mechanism to advance the science and capabilities needed for climate predictions and applications (building on the lessons of TOGA and its predecessors), but also as a way to thoughtfully and systematically link climate science with challenges associated with sustainable development and risk management in developing countries. For this reason, NOAA, initiated by the then-Director of the NOAA/OGP, (Dr. J. Michael Hall) purposefully sought out, and developed active partnerships not only with physical science research and operational entities but also with social scientists, natural resource managers, and government agencies with responsibilities for maintaining the health, public safety and food security of at-risk populations. While NOAA convened the 1995 Forum in conjunction with several other agencies of the USGCRP (and continues to collaborate with them), mission entities such as USAID, the World Bank, and the Inter-American Development Bank, quickly became - and continue to be - critical partners to whom NOAA looks for ensuring the relevance and usefulness of IRI's and NOAA's activities in terms of asking the "right" questions and providing the "appropriate" knowledge, capacity and decision support resources for ensuring the optimal use of climate information in decision making in these more vulnerable regions. In addition to focusing on ENSO, NOAA also was guided by an understanding that these shorter time scale challenges could be an entry point for working with stakeholders to understand their needs and capabilities for synchronizing them with our research priorities in the area of longer-term climate change. The long-term climate change topic was considered difficult to address in some cases because (until relatively recently) it was considered intangible, with limited attribution of regional climate extremes and impacts, and highly controversial in terms of the effect of human activity on this large complex natural system. On the other hand, governments, resource managers, and private citizens throughout the world could clearly see the physical and socio-economic impacts of ENSO, as they personally experienced two strong events discussed increasingly in the popular media - in the 1980s and 1990s.

NOAA was also interested in the IRI as a vehicle for learning how to best conduct science, link it to decision making, and incorporate the knowledge gained from these activities into ongoing research planning and implementation. The feedback from scientists and decision makers played a critical role in shaping the institutional structure and function of the IRI. In addition, these experiences ultimately informed and helped shape current international efforts such as the Global Framework for Climate 
Services (GFCS) (Global Framework for Climate Services). Finally this effort also provided valuable insights useful to NOAA's climate research, applications and prediction efforts. For example, the regional Pilot Applications Program and the RCOFs generated several key recommendations that shaped our efforts from the early 1990s to present day. Findings from this pilot phase demonstrated the following needs: a) improve forecast accuracy and detail; b) validate numerical models with in situ climate observations: c) train both producers and users of climate information; d) present information in an accessible manner (e.g., are terciles the best way to communicate with non-scientists?); e) develop and sustain networks of individuals and organizations in a region; and f) continued research into the socioeconomic context in which climate information may be used (Office of Global Programs, National Oceanic and Atmospheric Administration, US Department of Commerce 1996). The pilot applications projects and, most notably, the RCOF processes, had an impact on how countries and organizations responded to the '97-'98 ENSO event (e.g., USAID was able to position human resources in those countries considered most vulnerable in order to better coordinate a response). Not all experiences during this event were positive, but there are lessons to be learned, both, about appropriate entry points for climate information in preparedness and adaptation, and about the difficulties of sustaining long-term social and scientific networks. For example, in Southern Africa, countries raised public awareness of potential impacts through the NMHSs and regional organizations such as the Southern Africa Development Community, the USAID's Famine Early Warning System using food security analyses issued recommendations for reducing vulnerability, including utilizing more drought-tolerant crops, and high level policy meetings were held in the region. The United Nations and the USAID developed plans and positioned resources to be able to react quickly should the forecasted conditions of drought occur. In the end, more rain was received than initially forecasted in some regions and in a few cases, farmers lost potential profits as they planted reduced crops based on the forecast. However, there are important lessons to be offered by this event, including the value of countries working together to develop and distribute information, the need to approach the provision of all climate information with understandable parameters for uncertainty, as well as additional research on the benefits and challenges to harnessing climate science for risk management (Dilley 2000).

NOAA's long history of involvement in the development of IRI and related investments benefited NOAA and the domestic scientific and stakeholder communities with whom we work. The efforts to engage the disaster management and hazard mitigation communities, public health, economic and social development organizations, as well as meteorological service and scientists - much of which was sponsored as a means of informing the development of the IRI - shaped the development of both the global and the domestic efforts sponsored by NOAA. Just as the initial emphasis of the IRI was on improving modeling capabilities, but over time expanded to include a greater focus on applications development, capacity building, training and social/policy sciences - examples of which are included in this special issue - NOAA's climate program followed a similar path of expansion beyond understanding and predicting the physical climate system to embracing focused social science research and stakeholder involvement in recognition that a prediction alone - no matter how technically accurate - is not useful if issues such as impacts, vulnerability, institutional opportunities and barriers, and other contextual information are not considered in the design and use of this information.

In the late 1990s, even though the predominant emphasis on coupling climate and societal information was directed toward the world's most highly vulnerable populations, the USGCRP was conducting it's first national assessment of the impacts of global change and the NOAA/OGP was designing regional experiments in the US that could be problem-focused, ensure more localized climatic and hydrologic information, and include investigation of potential or actual responses to variability built into risk management frameworks. The experiences that led to the development of the IRI provided the confidence that a framework that brought practitioners and scientists into sustained working proximity would be essential to long term capacity and success in incorporating climate information in a routine fashion beyond the project phase. Measures as to how this is working are still being accumulated. Relevant research and investments in capacity to incorporate scientific information were viewed as a responsibility domestically and internationally.

In much of the developing world, communities experience coping through periods of extreme events, whether in semi-arid regions or flood prone areas highlighting the connections between civil society and climate variability and change. In addition, international efforts demonstrated the value of local information sources and the social and institutional benefits of moving from emergency response to more sustained and consistent risk mitigation (Magahalhães et al. 1993).

In addition to shaping elements of NOAA's climate and society research portfolio, NOAA investments such as those made in the IRI help advance the agency's programs focused on climate prediction and related products. Starting in January 2012, the National Centers for Environmental Prediction/CPC and the IRI joined forces to co-author the popular monthly ENSO Diagnostics Discussion, which updates the public on the status and prediction of ENSO. For 
nearly a decade prior to this, the IRI created many popular ENSO products that complemented the suite of ENSO products provided by the CPC. One of IRI's most visible products is the IRI ENSO prediction plume (Figure 1), that shows $\sim 25$ model forecasts of sea surface temperatures for the Nino-3.4 region in the east-central equatorial Pacific Ocean, which is used for NOAA's official ENSO index. IRI and CPC collaborate on specific products through a structured dialogue involving forecasters from each group (Figure 2). The IRI and CPC have continued to strengthen their coordination on operational ENSO products and discussions that are intended both for the general public and for more technical audiences. Collaboration between CPC and the IRI offers tangible benefits to the US and international communities, including the following: (1) strengthened forecast procedures for the production of the ENSO Diagnostics Discussion, (2) the development of new and improved tools that aid ENSO monitoring and prediction (essential to NOAA's mission); and (3) the expansion of the numbers and stakeholders that that rely on timely ENSO-related information products in the US.

\section{Value of international climate investments from the development perspective}

USAID is the lead agency in the US Government for providing support to developing countries. USAID also coordinates the US Government's response to natural disasters in developing countries. USAID has played an important role in shaping and expanding the direction of NOAA's international research and applications investments from the beginning of NOAA's regional Pilot Applications Program, including participation in some of the pilot applications projects and sponsorships of some of the earliest RCOFs. During the 1990s, the USAID Office of Foreign Disaster Assistance (USAID/OFDA) and NOAA worked together to advance these activities through an inter-agency agreement. In 2010, USAID's Global Climate Change Office began funding IRI directly for specific projects. USAID continues to work with NOAA in its international programs through the recently established International Research and Applications Project (please see description below).

Many developing country economies depend heavily on activities that are highly weather- and climate-sensitive. Agriculture dominates the economies of least developed countries, comprising as much as a third of Gross Domestic Product and providing for $60-80$ percent of livelihoods (African Development Bank Group; Kwa). A delay in the rainy season, or an unusually dry year can devastate crop production, impoverishing already poor people. Many middle-income developing countries depend on tourism for much of their economic activity. Some of the research generated in the early 1990s linking climate variability to agricultural management and food security in developing countries caught the attention of USAID as it presented a potential tool for use in fostering development, and helping countries plan for and adapt to extreme events such as droughts, floods and hurricanes (Cane et al. 1994).

USAID recognizes that in order to maximize the benefits of investments in agriculture, natural resource management,

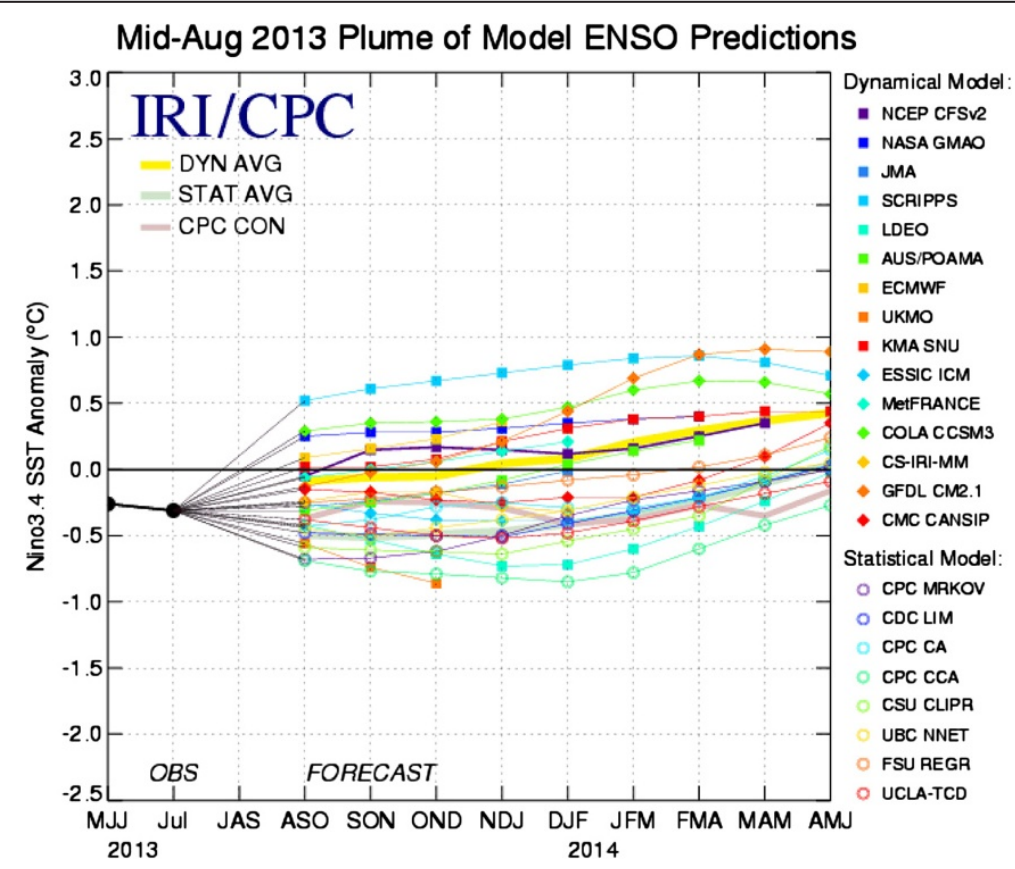

Figure 1 Example of Plume Model of ENSO Predictions. 


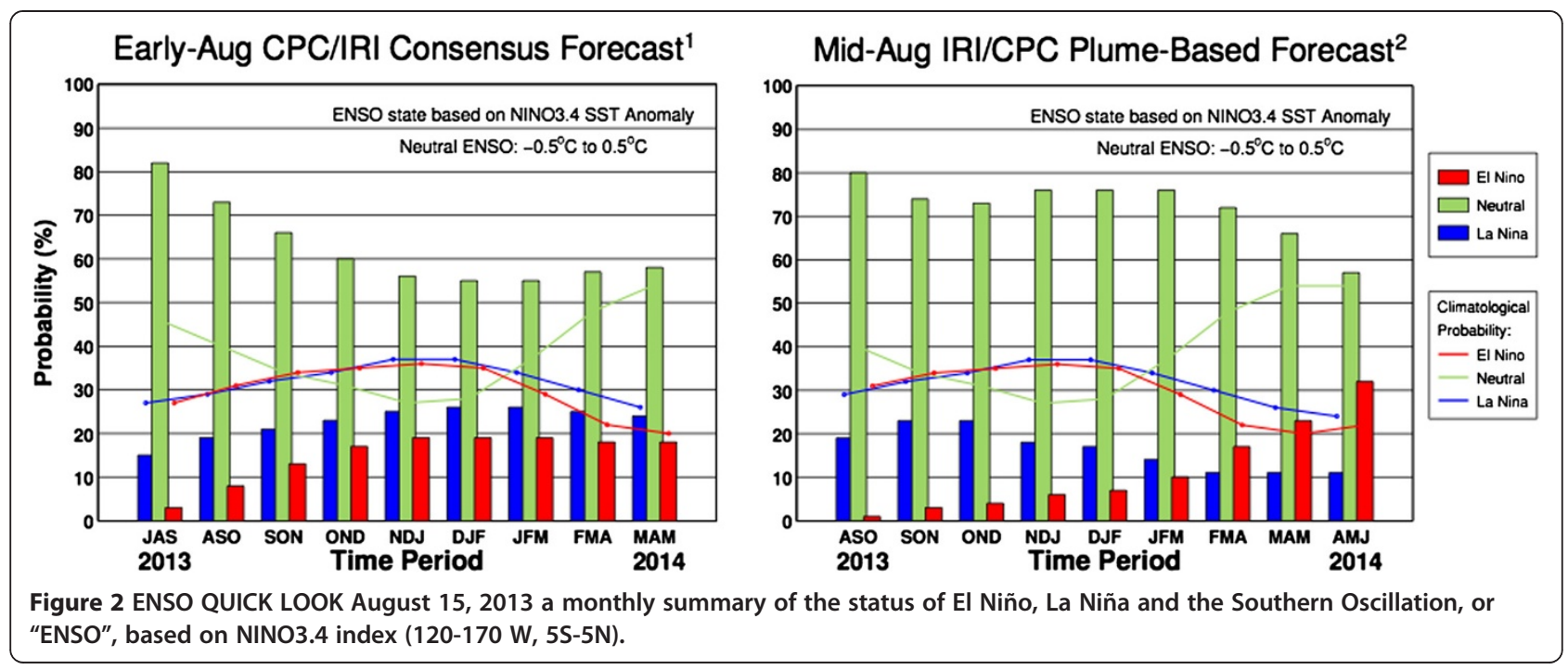

tourism, and other climate-sensitive sectors, we need to better understand and manage the risks posed by climate variability and change. In much of the developing world, a variety of obstacles exist to fully understanding current conditions, much less predicting future conditions. Weather data is incomplete; meteorological services are understaffed, under-resourced, undertrained; weather stations are sparse, and many either don't work or their data is not used. In one Caribbean country, for example, there is good coverage by weather stations, but the stations generate data in different formats, making it difficult to use in applications tools such as IRI's Climate Predictability Tool. In many countries in Africa, historical data is riddled with gaps, particularly in those years of the transition from Colonial rule to independence. Some records are available on paper, but not in digital format. Many weather services' staffs need training and equipment to effectively utilize what limited data do exist.

USAID has been working with NOAA and IRI to resolve a number of these issues and to develop tools to enable better decision-making by farmers, resource managers, and emergency managers. By collaborating with NOAA and IRI, and their partners, USAID is able to draw upon some of the best climate science in the world and jointly work on ways of applying it to the challenges of improving livelihoods in developing countries. The relationship enables NOAA and USAID to focus on their strengths while learning from one another. IRI plays an important bridging role between the two agencies.

With direct funding to IRI, USAID provides support for RCOFs in Africa, enabling IRI to offer additional training associated with these events. IRI is facilitating the digitization of decades' worth of weather records stored at the African Center for Meteorological Applications for
Development; once the data are digitized, IRI will help negotiate their public use with each sovereign country.

Beyond training and data management, USAID is working with IRI on the development of climate services for developing countries. Many NMHSs are caught in a vicious cycle of under-funding, under capacity, and low levels of service provision - the result of which is continued under-funding, low capacity, and ongoing inability to provide a high level of service. USAID is helping NMHSs provide a better level of service - even if it is just one new, useful product, and encouraging the joint production of information services tailored to needs of decision makers. IRI is critical to this work. Through IRI, USAID is supporting training of staff at the Meteorological Service of Jamaica and the Agriculture Extension Service to develop tailored drought forecasts and information that farmers can use in response to the forecast. The Meteorological Service of Jamaica and the Agriculture Extension Service have committed to a first product by the end of 2013. Elsewhere, USAID are following a similar model of connecting information consumers with information producers in the hope of supporting better decision-making.

USAID is also working with IRI and the insurance industry to bring weather index insurance to smallholder farmers. Index insurance differs from traditional indemnity insurance in that the payment depends on weather events, not damages. This type of insurance is cheaper to administer because there does not need to be an assessment of damages, just an accurate weather report. The insurance is meant to embolden farmers to take high yield risks in good weather years with the knowledge that, should the weather turn against them, they will have some of their losses covered. Such insurance works best when offered with risk-reducing practices, access to credit, and access to 
banking (savings). But underpinning it all is reliable, trusted weather and climate information.

USAID's partnership with IRI has expanded in the past several years. The agency is finding that climate services are a crucial - but under-explored - area for development assistance. USAID's work with IRI is filling critical gaps to support livelihoods and economic development in some of the poorest parts of the world.

\section{Future directions}

Today's landscape differs notably than that which existed in the early 1990s, when the IRI was still in its design phase, and NOAA initiated its first major investments in international climate research and applications development with its partner agencies and organizations. While the notion existed that experimental forecasts of the ENSO phenomenon would be relevant, and hopefully even helpful, in a number of sectors in the tropics such as agriculture and human health, we - as a community did not fully understand or appreciate the complexity of the challenges associated with applying climate information to decision making and the extent to which risks are constantly changing. Increasing demand for information about climate variability and change, and a corresponding evolution of capabilities within the scientific community, has helped drive and shape the creation of research, services, institutions, and networks designed to respond to a wide array of needs for useful climate information. The last two decades represents a global "experiment" of sorts in the provision of climate services within an evolving framework that conceptually spans, inter alia: 1) interdisciplinary scientific knowledge development and management; 2) capacity development and network coordination; 3) integrated products and services delivery; and 4) the development of adaptation and (increasingly) climate-aware development strategies, and their implications for monitoring, modeling and assessment activities.

And from experience of the last 20 years, we - as a global community - have learned a great deal about the value of: i) understanding and assessing vulnerability and decision support needs on a scale defined by the nature of the decision question; ii) listening to and valuing the input of stakeholders in our science; iii) enhancing the local/national/regional capacity to collect and interpret their own data and applications tools; and iv) the management of these types of complex programs. As we look toward the future, there are many opportunities on the horizon, including expanding predictability to include a seamless suite of products covering multiple timescales (across weather and climate, including subseasonal and multi-decadal); engaging stakeholders and developing usable information and capacity in sectors such as energy planning, private sector decisions, development and adaptation; and increasing the capacity and efficacy of early warning information systems.

In order to reflect upon the implications of these opportunities and challenges for the next phase of NOAA's international climate activities, the NOAA Climate Program Office (CPO; formerly the OGP) invited a diverse group of scientists, decision- makers, and other technical experts familiar with the multitude of efforts to link climate with society - including the IRI - to reflect upon the last 20 years of experience. The vehicle for this dialogue was the NOAA Workshop on International Climate Services: Understanding and Responding to the Needs of Decision Makers in September 2010 (Washington, DC). Several key themes emerged as central to developing a blueprint for the next generation of international applied climate research and services development that would most benefit practical efforts in community resilience, including the importance of the following: a) utilizing a collaborative process to identify and respond to user needs; b) emphasizing a multi-disciplinary decision support research as an integral component of end-to-end climate services; c) creating innovative partnerships to understand and address user needs; d) recognizing and addressing needs for training and capacity building of both the producers and users of climate information; d) prioritizing, assessing and evaluation activities on a regular basis as part of projects/programs; and e) fostering cooperation in data sharing, and service and product verification/ "certification" (Vaughan 2011).

Based on these discussions, and interactions with partners such as USAID and others, NOAA announced the establishment of the International Research and Applications Project (IRAP) in 2012. As NOAA core funding for the IRI ended in June 2013, IRAP represents the next phase in the agency's international research and applications program investment. Unlike funding for the IRI, IRAP will be supported through an interagency partnership between the NOAA and USAID's Climate Program (there is a high level of interest in expanding this partnership to USAID's missions and technical entities as well). This intent to jointly provide core funding is a meaningful science policy development; it will ensure that the combined investment will support activities that link climate research and assessments to practical risk management, development and adaptation challenges in key regions throughout the world.

The IRAP was formally launched in August 2013, when, following a competitive proposal process, a five-year cooperative agreement was established between the IRI, located at Columbia University, and NOAA/CPO. The IRI will co-lead the project with a multi-disciplinary team from the University of Arizona. Each university contributes unique expertise in the critical elements of developing integrated, research-based knowledge and information designed specifically for decision making needs, in a true 
partnership with stakeholders as active and valued participants. The team has strengths in both physical and social sciences, as well as expertise in communications, outreach and extension; policy development; capacity building and training; and evaluation. They will augment their own capacity through partnerships with a suite of international, regional, national and local organizations.

IRAP, essentially the next phase of NOAA's investment in international, interdisciplinary climate research for adaptation and development, is greatly influenced by the experience of decision support research and changing needs of practitioners as communities experience first hand the effects of extreme weather and climate variability over the last twenty years. For example, IRAP prioritizes specific geographical regions and several key societal challenges, in order to: 1) emphasize and sponsor sustained partnership development; 2) optimize the investment of resources and allow for substantial focus, partnership development, and a tractable connection with implementation; and 3) evaluation and analyses. For the initial five-year phase of the project, IRAP will focus on three regional priorities: the Caribbean, West Africa and the Indo-Gangetic Plain. Recognizing that many areas of the world face significant socio-economic impacts due to the effects of climate variability and change, NOAA, with input from USAID, selected these three regions based on a combination of conditions both within, and external to the agency, including, inter alia: existing scientific, technical and institutional capabilities and partnerships; emerging opportunities for research, cooperation and applications for adaptation and risk management; and the presence of opportunities to address a range of key climatic and development issues across multiple time scales. The project will seek out opportunities to leverage activities and develop mutually beneficial linkages to other climate-related activities in these regions, including those related to vulnerability assessments, impacts research, product and services development, planning, capacity building, training, coordination and adaptation, as well as to the development efforts undertaken by USAID and others. Given the changing landscape, the nature and scale of IRAP reflects current capabilities and global trends in developing climate services. Additional information about IRAP can be found on the Website of NOAA's Climate Program Office (NOAA's Climate Program Office, International Research and Applications Project).

\section{Conclusions}

The IRI was created in the early 1990s to realize climate-related opportunities and address information and capacity gaps identified by both the scientific and inter-governmental communities, and to serve as a resource to rapidly accelerate the science of climate monitoring and modeling, and the production, distribution, and application of climate products. Over the years, the IRI incorporated what they were learning on the ground, and expanded to include a greater emphasis on capacity building, training and understanding the socio-economic context (including the role of multiple stressors and elements of resilience) for this information. However, since the early days of the IRI, the demand for climate information has grown exponentially, creating a demand for greater capacity to meet these needs. As a result, there are more organizations, institutions and programs focused on various aspects of climate modeling, monitoring and information production. The IRI itself continues to be among the leaders in this innovative field and continues to be sought after by development organizations, public health networks, countries and sector specific-associations as a well-respected source of technical knowledge and expertise. Recognizing the potential value of climate information produced through international and interdisciplinary cooperation, and applied to enhance resilience, initiatives such as the Global Framework for Climate Services (GFCS) are emerging. The GFCS initiative is designed to foster the provision of climate information and predictions for applications in decision-making in climate-sensitive sectors and regions, at timescales ranging from seasons to decades. In parallel, many organizations (including those in the public and private sector), countries, and regions are developing their own strategies and approaches to climate services, which, ideally, would comprise the underpinnings and connective tissue of the broader, global climate services endeavor. After much consideration and evaluation of current capabilities and needs, NOAA chose to focus this next phase of its activities on the translation of existing information (integrated from various sources, including NOAA, the IRI and other climate research entities) into specific products and capacity in the context of adaptation and development needs. IRAP will utilize the expertise, methodologies and products already housed across the University of Arizona and the IRI at Columbia University to advance the development of knowledge and capacity that will help developing countries participate more effectively in the evolving international infrastructure and institutional frameworks that did not exist 20 years ago. We recognize that we are not "starting from scratch" but rather building on previous investments.

Finally, while the IRI experience offers a great deal of insight into the nature, design and implementation of climate services, it was conceptualized and managed as an "experiment" that would advance the science, our understanding of how to develop and use climate information and, ideally, improve the well-being of people living in the countries with which the IRI collaborated at the same time. This special issue highlights many of the lessons learned across the spectrum of producing and 
applying climate information. However, monitoring and evaluating the impact of a research-to-services program of this nature presents a substantial intellectual and resource-intensive challenge, with which many agencies and organizations struggle, including NOAA. Beyond peer-reviewed publications (which demonstrates the contribution to the scientific and research fields involved in climate science, adaptation and climate-informed development), how do we best measure, understand and translate the value of such investments in terms of societal impact? IRAP is tackling this challenge head on, in the first stages of the project by developing and testing an evaluation methodology. We are looking forward to looking back ten, twenty years from now with this data in hand, and as we are with this special issue, telling a story of substantial advances in the incorporation of climate science for the betterment of society.

\section{Endnotes}

${ }^{a}$ Throughout the 1990s, NOAA had supported specific studies to understand the connections between climate variability and societal challenges such as malaria, agricultural management and food security, fires and water management in developing countries. These pilot projects provided data and knowledge that could be used in conjunction with RCOF products to inform decisionmaking.

${ }^{\mathrm{b}}$ Participants included a broad range of multi-disciplinary scientists; technical, risk management and regional experts; international, regional, and national organizations and initiatives concerned with climate vulnerability and services; and representatives of development organizations.

\section{Competing interests}

The authors declare that they have no competing interests.

\section{Authors' contributions}

LFV developed the conceptual framework for the essay, drafting all of the sections other than those focused on the linkages between NOAA/CPC and IRI and the perspective of USAID. JF wrote the section on USAID's interests in the $\mid R I$ and the use of climate information. WH provided the input regarding the relationship between NOAA/CPC and IRI. CN contributed to all of the paper, with an emphasis on the Future Directions and Conclusion section. RP contributed to all of the paper, with an emphasis on the Future Directions section. All authors read and approved the final manuscript.

\footnotetext{
Authors' information

LFV is currently the Program Manager for the NOAA International Research and Applications Project; she has 20 years of experience developing and analyzing integrated climate applications research programs, with an emphasis on international endeavors. LFV played a leading role in the development and implementation of pilot applications activities, including the ' 97 '98 RCOFs, throughout Latin America and the Caribbean. JF is currently a Climate Change Specialist with the USAID, with a focus on climate adaptation programs, project design, and climate negotiations. $\mathrm{WH}$ is the Director of NOAA's Climate Program Office (CPO), serving as the focal point for climate programs within NOAA as well as international efforts such as the Global Framework for Climate Services. Prior to his selection as CPO Director, WH was the acting Director of the National Weather Service, National Centers for Environmental Prediction (NCEP) in 2013 and the Director of NCEP's Climate Prediction Center (CPC) from 2007-2013. RP is
}

currently the Director of the National Integrated Drought Information System (NIDIS) and heads up the NOAA/CPO Climate Assessments and Services Division. He has conducted applied research on climate, impacts assessments, and adaptation, and managed interdisciplinary research programs focused on the development of early warning information systems. $\mathrm{CN}$ has over 20 years of experience in the intellectual and conceptual design and management of a broad spectrum of programs dealing with the interface of climate and society, with an emphasis on societal impacts and adaptation. She has facilitated the development of international and inter-agency efforts focused on these issues with notable success. All of these individuals have played key roles in the development of the programs/institutions addressed in this essay, including IRI, the USAID-IRI collaborative efforts, RISA, RCOFs, CPC, etc.

\section{Acknowledgements}

The authors wish to thank the Editorial Staff of Earth Perspectives.

Responsible editor: Ghassem Asrar.

\section{Author details}

${ }^{1}$ Climate Program Office, National Oceanic and Atmospheric Administration, US Department of Commerce, 1315 East-West Highway, Silver Spring, MD 20190, USA. ² Global Climate Change Office, US Agency for International Development, Department of State, 1300 Pennsylvania Ave NW, Washington DC, DC 20523, USA. ${ }^{3}$ Climate Program Office, National Oceanic and Atmospheric Administration, US Department of Commerce, 325 Broadway, Boulder, CO 80305, USA.

Received: 1 October 2013 Accepted: 4 March 2014

Published: 17 June 2014

\section{References}

African Development Bank Group Agriculture Sector Strategy 2010 - 2014. [http://www.afdb.org/fileadmin/uploads/afdb/Documents/Policy-Documents/ Agriculture\%20Sector\%20Strategy\%2010-14.pdf]

Buizer JL, Foster J, Lund D (2005) Global impacts and regional actions: preparing for the 1997-1998 El Niño. Bull Am Meteorol Soc 81:2121-2139

Cane M, Eshel G, Buckland R (1994) Forecasting Zimbabwean Maize Yield Using Eastern Equatorial Pacific Sea-Surface Temperature. Nature 370(6486):204-205

Dilley M (2000) Reducing vulnerability to climate variability in Southern Africa: the growing role of climate information. Clim Chang 45:63-73

Glantz M (1995) Forecasting El Niño: Science's Gift to the $21^{\text {st }}$ Century. Ecodecision 12:78-81

Glantz M (2000) Currents of Change: Impacts of El Niño and La Niña on Climate and Society, 2nd edn. Cambridge University Press, Boston

Global Framework for Climate Services [http://www.gfcs-climate.org/]

JSC/CCCO TOGA Scientific Steering Group (1990) Report of the Eighth Session, 18-20 September 1989. World Meteorological Organization, Geneva

Kwa A Agriculture in Developing Countries: Which Way Forward? In: TradeRelated Agenda, Development and Equity (T.R.A.D.E.) Occasional Papers 4 South Centre 2001. [http://focusweb.org/publications/2001/agriculture_ which_way_forward.html]

Magahalhães AR, Neto EB, Panagides SS, Schmandt J (1993) Climate and Sustainable Development in Brazil's Semi Arid Northeast: Assessment and Response Options. In: Proceedings of the Annual Meeting of the American Association for the Advancement of Science

National Research C (1999) Making Climate Forecasts Matter. The National Academies Press, Washington, DC

National Research Council (1996) Learning to Predict the Climate Variations Associated with El Niño and the Southern Oscillation. The National Academies Press, Washington, DC

National Research Council (2001) A Climate Services Vision: First Steps Toward the Future. The National Academies Press, Washington DC

NOAA Office of Global Programs (1996) Proceedings of the International Forum on Forecasting El Niño: Launching and International Research Institute; 6-8 November 1995. University Corporation for Atmospheric Research, Washington, DC

NOAA's Climate Program Office, International Research and Applications Project [http://cpo.noaa.gov/ClimatePrograms/ClimateandSocietallnteractions/ IRAPProgram.aspx]

Office of Global Programs, National Oceanic and Atmospheric Administration, US Department of Commerce (1996) An Experiment in the Application of 

Event

Pulwarty R, Simpson C, Nierenberg C (1999) Regional Integrated Sciences and Assessments (RISAs): Crafting Assessments for the Long Haul. In: Jager J (ed) Integrated Regional Assessments of Global Climate Change. Knight. Cambridge Press, Boston, pp 367-394

Ropelewski C, Halpert M (1987) Global and regional scale precipitation patterns associated with the El Niño/Southern Oscillation. Mon Weather Rev 115:1606-1626

Task Group for the International Research Institute for Climate Prediction (1992) A Proposal. The University Corporation for Atmospheric Research, Boulder

Testimony of J. Michael Hall, Director, Office of Climatic and Atmospheric Research, Office of Oceanic and Atmospheric Research, National Oceanographic and Atmospheric Administration, U.S. Department of Commerce (1987) Before the Subcommittee on Science, Space and Technology and the National Ocean Policy Study Committee on Commerce, Science and Transportation, United States Senate Cong, 1, (testimony of J. Michael Hall). Printed Copy

The National Oceanic and Atmospheric Administration (1994) A Proposal to Launch a Seasonal-to-Interannual Climate Prediction Program. The US Department of Commerce, Washington, DC

The NOAA Panel on Climate and Global Change (1989) The Vision: A Rededication of NOAA. The University Corporation for Atmospheric Research, Boulder

United States Government (1992) U.S. Actions for a Better Environment: A Sustained Commitment

US Global Change Research Program [http://www.globalchange.gov/about/ global-change-research-act]

Vaughan LF (2011) Report on a NOAA Workshop on International Climate Services: Understanding and Responding to the Needs of Decision Makers:27-29 September 2010. NOAA/CPO Website Document, Washington, DC [http://cpo.noaa.gov/sites/cpo/SARP/Final\%20International\%20Climate\% 20Services\%20Workshop\%20Summary\%20Report.pdf]

World Bank climate change programs [http://www.worldbank.org/en/topic/ climatechange]

World Health Organization climate programs [http://www.who.int/topics/climate/ en/]

doi:10.1186/2194-6434-1-23

Cite this article as: Vaughan et al:: US Investments in International Climate Research and Applications: reflections on contributions to interdisciplinary climate science and services, development, and adaptation. Earth Perspectives 2014 1:23.

\section{Submit your manuscript to a SpringerOpen ${ }^{\circ}$ journal and benefit from:}

- Convenient online submission

- Rigorous peer review

- Immediate publication on acceptance

- Open access: articles freely available online

- High visibility within the field

- Retaining the copyright to your article

Submit your next manuscript at $\gg$ springeropen.com 